\title{
Integrated Learning Through Experience: Sports Marketing Education Is All About The Little Things
}

Eric J. Newman, (Email: enewman@csusb.edu), California State University, San Bernardino Fred Hebein, California State University, San Bernardino

\begin{abstract}
The fun and exciting business of sports entertainment is continuing to grow with sales revenue in the billions. Sports entertainment is serious business with increasing demand for knowledgeable marketers willing to work hard in a very fun but stressful environment. After working and experiencing the stadium, the fans, and the related business activities, the students realized that their projects were real and could have important impacts. With the integration of this knowledge and experience, the students started building mini-marketing plans that were feasible project ideas that could be implemented with management sponsorship. Another important result was the student realization that the managers and employees who were required to implement the project ideas had no extra time or extra resources. The project had to gain the support of the managers and employees at the expense of other projects and in addition to their regular business assignments
\end{abstract}

\section{INTRODUCTION}

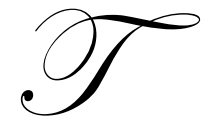

he fun and exciting business of sports entertainment is continuing to grow with sales revenue in the billions. Sports entertainment is serious business with increasing demand for knowledgeable marketers willing to work hard in a very fun but stressful environment. In the past, sports managerial offices were filled with retired athletes -- but times have changed. In today's competitive entertainment environment, the teams are hiring business and marketing majors to develop the sports business, to provide customer service and to gain and retain consumers. The ability to develop a business, to provide customer service and to gain and retain consumers, often depends upon doing the little things right.

\section{COURSE OBJECTIVES}

To prepare students for sports marketing careers, our goal was to design a course that would provide a theoretical foundation for sports marketing with significant practical training. We believed that a dose of reality through experience in actual sports marketing would better prepare students for sports marketing careers, while it would also help some make better decisions about career choices - sports marketing careers are not for every one. Attending a sports game may be fun-but attending and working at every game may become a chore-sports marketing may actually be hard work!

As we designed the course, the objectives could be summarized into three main areas. First, we wanted the students to integrate their knowledge through experiential learning. It is well recognized that experience is an important part in the learning process (Dewey 1938). Furthermore, the students need to be able to demonstrate their capacity to transfer skills learned in academics programs to their work situations (Stewart and Knowles 2000).

An integrated learning environment provides a synergistic combination of work experience plus academic knowledge. The students apply the knowledge gained through lecture and written works such as books and articles to real world situations. The integration provides a stronger and more successful learning environment than either work 
or academics alone. Integrated learning has even been conceptualized as an idealized learning cycle where the learner "touches all the bases" (Kolb and Boyatzis 2001).

The second course objective was to make students more realistic about business strategy and outcomes. For example, most text and case examples are corporate. The projects discussed are large and cover all aspect of the companies' marketing strategy. While the general need of academic work is to be comprehensive, particularly in instruction, such examples insufficiently emphasize that businesses find small projects profitable and important because such projects address immediate needs.

Often students become convinced that the only way to be successful in the business world is to develop a new and comprehensive strategy. The belief by students that vast changes are always necessary and preferable leads them to propose strategies that are too broad, often impractical to implement, and occasionally suspect as to profitable return. As we will discuss later in the paper, student proposals became more realistic and doable as the students gained experience.

The third objective was to encourage continuous learning. Managers for the baseball team involved in our business partnership emphasized their requirements for employment. The managers wanted a business major who understood baseball, with common sense and a desire to learn. Management revealed that they are continuously learning as operations increasingly get more complex and with higher service demands.

Employees who can learn on a continuous basis adapting to the changes of increasingly complex demands and service requirements are the most sought after (Kelly 1999). The need for continual on the job learning and flexibility is a requirement for both sanity and success. The integration of academic skills, experience, and newly acquired skills are vital for business success.

\section{ACADEMIC FOUNDATIONS: TEXTBOOK AND LECTURES}

In general, sports marketing textbooks are designed to be comprehensive in their review of marketing material. We select books appropriate for students who are senior and graduate level marketing majors. Since sports marketing textbooks are designed to stand alone and cover all aspects of sports marketing, students often find them full of "repetitive information". Students have already been introduced to similar topics in other courses. Interestingly, students initially report that they consider the book as twenty percent useful but somewhat "boring" because they already have been introduced to about eighty percent of the information.

However, when the projects begin, the instructors note that many students refer to the text to "refresh" themselves on previously learned subjects. Since repetition and reapplication of previously learned material enhances overall learning, comprehensive textbooks, while occasionally demeaned by students, offer important resources as students integrate previously encountered material into new experiences. Consequently, we prefer comprehensive marketing sports textbooks.

Lectures are important elements in the integration of knowledge and experience. The flexibility of lectures permits the explanation of sports marketing topics and how such topics relate to the student projects upon which the students are working. That is, concepts are related to the execution of plans. In particular, lectures emphasize how small changes can have large impacts on the success of businesses in general and sports marketing programs especially.

\section{SELECTION OF A BUSINESS PARTNER}

In a forthcoming publication (Newman and Hebein, 2004), we discussed the identification, selection and development of mutually satisfying business partnerships. In addition to providing opportunities for students, business partnerships are vital associations for the university and provide important relationships with business and community leaders. For the purposes of this paper, our business partner is a local minor league baseball team. 
The baseball team provided season passes to the project teams (students) so that the students could attend all scheduled games for free. In addition to this access, the students also met with the managers and were provided with a tour of the business offices and the stadium. The managers answered questions about the stadium and team goals. The managers also provided information on employment opportunities. The baseball team management agreed to full access to their stadium for the experiential component of the course.

Access to the stadium provides the opportunity for the students to experience different styles and environments. The matching of those two components has proven to be very important in employee job satisfaction and performance (Kolb and Boyatzis 2001).

In addition, the work experience gave the students the opportunity to understand the business environment in which they were working. As the students developed their project ideas, they had the opportunity to test their project concepts with fans and employees. The work experience opportunities provided some reality checks. While attending the games, the students were occasionally asked to perform small duties and were encouraged to "tag along" with and support mid-level management. On these occasions, the students learned that even managers clean toilets or mop up "regurgitated hotdogs" when needed.

The students were required to attend the games throughout the course. The season passes were shown at the ticket window to receive game tickets. The students were asked to sit next to regular fans and season ticket holders. They were to listen to the fans and visit with them about the game, stadium, and experience. They were also asked to perform minor duties such as handing out coupons or promotional items. These activities provided student interaction with the consumers and the opportunity to learn on the job.

\section{ACADEMIC REPORTS AND GRADING}

Students reported on their discoveries, findings, and experiences in class through lecture discussions, written papers, and exam essay questions. The papers and exam questions forced the students to reflect on the situations they encountered. Of great importance to measuring learning, the students discussed how their ideas changed throughout the project as they experienced more. As other researchers have noted, successful integration of knowledge and experience requires experiencing, reflecting, thinking, and acting in a repeated process that is responsive to the learning situation (Kolb and Boyatzis 2001).

Reflection has been shown as a key component to learning (McGill and Beaty 1995). Throughout the term, lecture and discussion noted the changed attitudes and perceptions among students toward the business. Furthermore, comparisons of beliefs during the academic term showed reevaluation towards more realistic expectations regarding sports marketing activities. Clearly, during the months of the project, the students were reflecting over their experiences. The change in attitudes, perceptions and beliefs suggest that the term provided adequate time for student reflection, which has been recognized in the literature as an important aspect in the learning process. (Dwerryhouse 2001)

\section{QUALITATIVE AND QUANTITATIVE EXERCISES}

To learn more about the consumers, the students were required to gather basic qualitative information during their conversations with fans. Qualitative/ethnographic research requires time to develop a relationship and trust. Often, the students were too anxious to get their questions answered without spending the time needed to build trust and the students experienced failure (another good learning tool!).

The instructor provided demonstrations on gathering ethnographic information. Classroom examples were presented and demonstrations were shown between the instructor and students. In the stadium, students sat close to the instructor to observe the conversation with the fans. Many students commented that they were surprised that a single question was not asked for over an hour after arrival. Once the relationship was built and minor trust was acquired, the fans started supplying information freely. The fans volunteered information that was very useful and honest. 
In gathering ethnographic information, a slow process is required to gain trust and a relationship (Measor and Woods 1991). In these exercises, the students learned the value of academic research (takes time to build trust), observed the successful gathering of information, and finally executed the task themselves.

The students also had to survey fans with quantitative survey instruments. The students were assigned to stadium sections to ask each fan to fill out a survey. The students were not allowed to answer any questions other than why it was administered and what the fans received for participation. But the students were required to listen to participants while the participants filled out the survey to gain any additional information, some of which may not be included in the survey. Following the execution of the survey, the students performed data entry and statistical analysis to be used in their final project assignment.

\section{OBSERVED RESULTS}

A profound result of the work experience was that student projects were changed from their initial proposals to more practical and more useful projects. After working and experiencing the stadium, the fans, and the related business activities, the students realized that their projects could be real and could have important impacts. The students also understood that the projects could not be as large as the comprehensive corporate cases that the students had studied. With the integration of this knowledge and experience, the students started building mini-marketing plans that were feasible project ideas that could be implemented with management sponsorship.

Another important result was the student realization that the managers and employees who were required to implement the project ideas had no extra time or extra resources. The project had to gain the support of the managers and employees at the expense of other projects and in addition to their regular business assignments.

\section{STUDENTS SELF-ASSESSED KNOWLEDGE OF THE LITTLE THINGS}

Students provided many unsolicited comments on their overall experience. Many realized that they finally understood the importance of being aware of all the little things involved in the sports fan experience. For example, simply having the ushers pass trash bags down the isles provided a cleaner seating area, which encouraged fans to purchase more treats, while it made an easier time for the cleaning crew. A second example was asking the venders to slow down and look around more for the fans when walking in the stadium sections. By permitting the vendors to go slower, the fans felt greater rapport with the vendors, found it easier to ask for food and merchandise, and purchased more from the vendors.

Here are a few students' comments:

- $\quad$ Now I get it, you kept talking about how it is the little things that matter but I didn't believe it until we talked with the consumers and experienced what they were really going through and what we could do about it.

- We just wrote a mini-marketing plan that is going to take very little time and very little expense and it is going to make a big difference because they are going to implement it.

What the students really enjoyed were the client comments, such as:

- Wow, ideas that we can actually implement!

- We have had a large number of student marketing plans provided to us including two projects last quarter by two different groups. This is the first time we were given some really good ideas we can afford and implement.

- We would like to hire some of the students to help implement the changes. Can we have copies of everything? 


\section{SUMMARY}

The integrated experiential learning approach was very successful in terms of student learning. (It also required a lot of time and planning by the faculty member - so beware!). Overall, the students were more confident about their ability and desire to work in the sports marketing environment. Many of the students stated that they learned so much by having to justify how to implement their ideas and that they felt more confident in their abilities. There is evidence that students with more confidence in their ability to learn and accept responsibility for their learning adopt a continued learning approach (Watkins 2001).

The goal of the course was to provide an interactive integrated experiential learning environment that provided the confidence and experience required to work in sports marketing. There were, of course, a number of students who realized that sports marketing was not what they expected and that they were no longer interested in the field of sports marketing. However, a number of students enjoyed the work and discovered that they were compatible with the management of the minor league team. Many of these students were hired at the end of the course in sports marketing careers.

\section{REFERENCES}

1. Dewey, J. (1938). Experience in Education. New York: Macmillan.

2. Dwerryhouse, R. (2001). "Real work in the 16-19 curriculum: AVCE business and young enterprise." Education and Training, 43 (3) 153-161.

3. Kelly, K. (1999). New rules for a new economy: 10 radical strategies for a connected world. New York: Viking Press.

4. Kolb, D. and Boyatzis, R. (2001). "Experiential learning theory: Previous research and new directions." in R.J. Sternberg, and L.F. Zhang (Eds.): Perspectives of Thinking, Learning, and Cognitive Styles. Mahwah, NJ: Lawrence Erlbaum, 227-248.

5. McGill, I and Beaty, L (1995). Action Learning, $2^{\text {nd }}$ ed., Kogan Page, London.

6. Measor, L. and Woods, P. (1991). "Breakthroughs and blockages in ethnographic research: contrasting experiences during the changing school's project", in Walford, G (ED.), Doing Education Research, Routledge, London.

7. Newman, E. and Hebein, F. (2004). "Business Partnering: New Horizons in Interactive Experiential Learning", Proceedings, Mountain Plains Management Association.

8. Stewart, J. and Knowles, V. (2000). "Graduate recruitment and selection: implications for HE, graduates and small business recruiters", Career Development International 5 (2) 65-80.

9. Watkins, D. (2001). "Correlates of approaches to learning: A cross cultural meta-analysis." in R.J. Sternberg, and L.F. Zhang (Eds.). Perspectives of Thinking, Learning, and Cognitive Styles. Mahwah, NJ: Lawrence Erlbaum. 


\section{Notes}

